\title{
Ilustração, experimentalismo e mecanicismo: aspectos das transformações do saber médico em Portugal no século XVIII
}

Jean Luiz Neves Abreu

Os "estrangeirados" e a defesa do experimentalismo na medicina

Um dos enfoques privilegiados pela historiografia nas últimas décadas tem sido o das questôes relacionadas à medicina no mundo luso-brasileiro, com ênfase nas relaçôes entre o saber médico e a cultura científica no século XVIII. ${ }^{1}$ Parte de uma pesquisa mais ampla sobre o tema, ${ }^{2}$ este artigo tem por objetivo apresentar algumas consideraçōes acerca da influência do experimentalismo e do mecanicismo nos estudos médicos do período, enfatizando seus desdobramentos no entendimento do corpo e da doença.

Durante grande parte do século XVIII a medicina luso-brasileira foi marcada pelas influências da concepção hipocrático-galênica. ${ }^{3}$ A então denominada "patologia humoral" concebia o corpo humano como um microcosmo por conter dentro de si as qualidades dos quatro elementos da natureza. A partir dessa teoria, a regulação das três partes principais do corpo - fígado, coração e cérebro - dependia do equilíbrio entre os quatro humores primários - sangue, cólera, fleuma e melancolia. As qualidades dos humores, por sua vez, eram estruturadas por pares de oposição: seco/úmido, frio/quente, delgado/grosso, doce/amargo; e as suas funçôes eram exercidas por relação de simpatia com determinados órgãos. Segundo essa perspectiva, a causa da doença residia na alteração de um ou mais humores que afetavam todo o microcosmo do corpo humano. ${ }^{4} \grave{A}$ influência do galenismo, cabe acrescentar ainda o papel da astrologia, da magia e das concepções sobrenaturais no saber médico da época. Embora tais aspectos não se limitassem à medicina portuguesa, o fato é que a cultura lusa se manteve relativamente fechada às inovaçôes da ciência ocorridas em 
diversos países da Europa, o que se devia, principalmente, à influência da escolástica e da Igreja católica na universidade. 5

Os médicos formados na Universidade de Coimbra durante muito tempo sorveram seus conhecimentos dos autores da Antigüidade, como Hipócrates, Galeno e de seus comentadores árabes, como Avicena. No período anterior à reforma dos Estatutos, em 1772, predominava na Universidade de Coimbra o estudo da ciência subscrita pelas autoridades e arquivada nos tratados. A intenção não era elaborar novos saberes, mas preparar os profissionais competentes para atuar segundo o conhecimento preestabelecido. As ciências exatas e naturais eram consideradas menores e a discussão escolástica substituía a experimentação. Além disso, a Inquisição e os jesuítas exerciam influência no ensino universitário desde 1555, criando obstáculos à renovação cultural. ${ }^{6}$

Desde meados do século XVIII, a medicina praticada em Portugal se tornou alvo de diversas críticas, sobretudo por parte dos "estrangeirados", letrados que tinham entrado em contato com a ciência praticada no restante da Europa e cujas idéias estão associadas com a problemática da Ilustração. ${ }^{7}$ Luís Antônio Verney, clérigo português radicado na Itália e exemplo de intelectual que viveu boa parte de sua vida fora de Portugal, fez da sua obra Verdadeiro método de estudar (1746) um verdadeiro libelo acusatório contra o ensino praticado na Universidade de Coimbra. ${ }^{8}$ Ao longo da obra, Verney se posiciona criticamente sobre cada ramo de saber e propõe mudanças para o exercício da gramática, matemática, física e outros campos de conhecimento, como a própria medicina. Verney apresentava, assim, um programa enciclopédico de reforma pedagógica, assentado na crítica ao isolamento cultural de Portugal e na defesa do racionalismo de raiz newtoniana, em oposição ao aristotelismo. ${ }^{9}$

As observaçóes que o autor faz acerca da medicina e da anatomia ressaltam os prejuízos que a filosofia peripatética, vinculada ao aristotelismo, trazia para o estudo do corpo humano. Para Verney estava claro que o ódio dos galênicos à anatomia provinha dos princípios que beberam da filosofia peripatética, "que finge que a natureza é aquilo que leram nos seus livros; e depois, reduzem tudo o que observaram na natureza aos princípios que têm bebido". ${ }^{10}$ 
Outro "estrangeirado" que propunha a renovação do ensino em Portugal era o médico cristão-novo Antônio Nunes Ribeiro Sanches, o qual também viveu grande parte de sua vida fora de Portugal. Em razão de sua origem judaica e com o intuito de aprofundar seus estudos, o médico saiu de Portugal em 1726. Esteve em vários países, como Inglaterra e França, e, em 1730, foi para a Universidade de Leiden, na Holanda, onde se estabeleceu por alguns anos, mantendo contato com o renomado médico Boerhaave, seu principal preceptor. Por indicação de Boerhaave, dirigiu-se para a Rússia e exerceu aí atividade médica durante vários anos, retornando para Paris em 1747.

Considerado um dos representantes do Iluminismo aplicado à medicina, contribuindo inclusive para a Enciclopédia de Diderot, Ribeiro Sanches foi autor de relevantes obras em que propunha reformas na medicina do Reino. ${ }^{11}$ Assim como Verney, ele considerava que o ensino da universidade não oferecia condições para formar profissionais necessários ao reino de Portugal, pois “a Faculdade de Medicina que existe em Coimbra é insuficiente para aprender o que necessita o naturalista, o físico, o químico, o médico e o anatomista". ${ }^{12}$

A afirmação acima foi extraída de Cartas sobre a educação da mocidade, obra publicada em Paris, em 1760, e enviada para Portugal ao diretor-geral de Estudos, Principal Almeida. Além dessa obra de caráter pedagógico mais abrangente, Ribeiro Sanches foi autor de um livro específico, escrito com o propósito de contribuir na reforma do ensino da medicina, Método para aprender e estudar a medicina (1763), no qual, à semelhança de Verney, pretendia "destruir o costume de convencer [...] de se decidirem as matérias mais importantes pela autoridade dos doutores". ${ }^{13}$

O método proposto por Ribeiro Sanches assentava-se no estudo da física e da geometria; um método de pensar fundado no "conhecimento interior provado pela experiência”. Inspirado nas lições de Boerhaave, o autor estipulava a necessidade de estudos preparatórios: o conhecimento da física geral e experimental, da química, da anatomia e da história da medicina. Indicava ainda a necessidade da construção de estabelecimentos científicos, como um teatro anatômico, um laboratório químico e uma botica. Além disso, conferia atenção especial à clínica médica e à cirurgia. A respeito da anatomia, considerava que ela era a porta de entrada para o médico penetrar no corpo são e enfermo. ${ }^{14}$ 
Se as opiniōes desses autores explicitam a oposição ao ensino praticado na Universidade de Coimbra, comungavam também da intenção em difundir outras concepções do saber médico em Portugal. Afinados com o ideário iluminista, os letrados pretendiam introduzir os princípios da ciência moderna, ligados ao experimentalismo e ao mecanicismo, em substituição aos princípios da medicina hipocrática, considerada ultrapassada.

Além de Verney e Ribeiro Sanches, compartilhava tais idéias o médico Jacob de Castro Sarmento. Expatriado em Londres por sua condição de judeu, Castro Sarmento teria sido convidado por d. João V para reformar a medicina e divulgar as idéias da ciência moderna em Portugal. De início, esse processo de renovação cultural ocorreria com a tradução do Novum Organum, de Francis Bacon. Entretanto, por razões desconhecidas, só foram impressas as primeiras páginas da obra. Embora esse projeto de Jacob de Castro Sarmento não tenha obtido sucesso, ele publicaria em 1735 Matéria médica, obra relevante para a divulgação de novas teorias da medicina, como a iatromecânica e os ensinamentos de Boerhaave. ${ }^{15}$

Contrário aos médicos peripatéticos e aos antigos sistemas do saber médico, Sarmento dizia-se vincular aos "princípios mecânicos". Asseverava ser a filosofia dos modernos firmada na observação da natureza, em contraposição à dos antigos, fundada na imaginação:

[...] no nosso presente e feliz século nos tem mostrado a falsidade destes sistemas todos, o trabalho e incansável estudo dos médicos mecânicos. É esta a presente seita experimental de filósofos, os quais, na parte especulativa, em lugar das conjunturas, fundam a sua sabedoria toda em experiências, nem admitem coisa alguma que não possam trazer à demonstração, e evidências, ajudados de experimentos filosóficos, químicos, anatômicos; e aos princípios gerais que não podem padecer a menor dúvida, chamam princípios mecânicos ou leis da natureza. ${ }^{16}$

As idéias de Castro Sarmento provavelmente tiveram maior repercussão na segunda edição da obra, em 1758, contexto em que as propostas de reformas ganhavam maiores contornos, apoiadas pelo consulado pombalino e pelo rei d. José I. As idéias inovadoras de Sarmento vieram acompanhadas de críticas à medicina praticada até então em Portugal. Jacob de Castro Sarmento fazia referências negativas aos remédios receitados pelos 
médicos portugueses de sua época, vinculados à medicina hipocrática e galênica. Um dos médicos que se tornou objeto das críticas de Sarmento foi Francisco da Fonseca Henriques, questionado sobre os efeitos de uma certa argila "estremotia": "Em quanto à virtude bezoártica, que lhe atribui o Dr. Francisco da Fonseca é imaginária, porque nem achamos fundamento algum para admiti-la, nem o mesmo autor falou por exame que ficasse na dita terra, ou por observação própria." ${ }^{17}$

Castro Sarmento dava grande relevância à observação da natureza, devendo esta se sobrepor ao juízo das autoridades. Incorporava os preceitos mecanicistas e experimentais da medicina, valorizando a química como meio de garantir a aplicação dos remédios para enfermidades específicas. Dessa maneira, sugeria aos professores de medicina "examinar cada um dos símplices, [...] até conseguirem o verdadeiro conhecimento de suas virtudes, para aplicá-los em umas, e evitar o seu uso, em outras enfermidades" ${ }^{18}$

Verney, por sua vez, condenava os medicamentos elaborados por João Curvo Semedo, um dos médicos portugueses com influência na medicina praticada em Portugal e nos domínios coloniais. ${ }^{19} \mathrm{O}$ clérigo ridicularizava Curvo Semedo porque ele usava como medicamento o óleo de nabos sem comprovar se o efeito provinha do nabo ou da utilização de um óleo qualquer. "Se ele me provasse isto, então veria o que havia de responder; enquanto não prova, devo dizer que todos os 58 anos de prática não concluem nada." Ao tecer tais comentários sobre os remédios de Curvo Semedo, o que estava sendo posto em questão era o método na verificação dos efeitos dos remédios no organismo humano. Nessa mesma perspectiva seguem as advertências aos usos de remédios cujas composições não seguiam critérios "científicos", propondo efeitos miraculosos. Nesse sentido, as triagas, remédios elaborados com o propósito de curar diversas enfermidades, também foram alvos de contestação por parte de Verney, "não entendendo como possa ser a triaga antídoto universal, obrando os venenos por tão diferentes maneiras". Da mesma forma, ridicularizava a farmácia à base de animais e as pedras de bezoar, que custavam muito dinheiro e apenas serviam "de sujar a água em que se desfazem" ${ }^{20}$

Embora fosse clérigo, Verney procurava dissociar a relação entre os milagres e a cura de certas doenças. Afirmava que nunca havia passado 
"pela imaginação querer que os médicos tivessem a virtude de fazer milagres, ou de emendar os defeitos da natureza corrupta pelo pecado". Afinal, havia muitas doenças incuráveis, de forma que muitos morriam pela "necessidade da natureza", assim como muitos se curavam pelo "benefício da medicina". ${ }^{21}$ Colocava em suspeita também os efeitos dos remédios utilizados para curar malefícios: "que os fumos dos dentes da caveira são bons para os homens que estão ligados para os atos matrimoniais: Se o estar ligado é efeito do demônio, como eles supõem, que tem que fazer a caveira com o demônio?"22

Em uma época em que se atribuía ao demônio o poder de agir sobre os corpos, a posição de Verney indica como alguns clérigos em Portugal se afinavam com a perspectiva racionalista do Iluminismo. Verney não seria o único eclesiástico a questionar os excessos das explicaçōes sobrenaturais para as doenças e a utilidade de certos remédios no combate às alteraçôes no corpo. Márcia Moisés Ribeiro mostrou que para o Estado português representado por d. José I a atuação de um clero ilustrado foi importante para a adequação da cultura ibérica à ciência das Luzes, ao permitir dissipar um sistema de crenças e valores considerados ultrapassados. ${ }^{23}$

Ribeiro Sanches compartilhava de opiniōes semelhantes às de Verney. Segundo afirmava, seriam necessárias várias experiências para atestar a eficácia de um remédio, pois "o médico que adquiriu uma vez um certo e rasteiro método de curar com sangrias, Água de Inglaterra, soro de leite, se for bem-sucedido com trinta enfermos, não quererá estudar, nem saber mais". ${ }^{24} \mathrm{Na}$ sua proposta de criar um tribunal de medicina, um dos problemas a ser enfrentado dizia respeito à falsificação de medicamentos. Ribeiro Sanches discorria particularmente sobre os abusos e prejuízos decorrentes dos segredos, remédios cujas fórmulas eram secretas e ficavam restritas ao conhecimento de seus fabricantes. ${ }^{25}$ Argumentava que se acaso o Estado autorizasse a venda de segredos, não seria necessário investir em tantos gastos com o curso de medicina, pois a anatomia, a botânica e a patologia tornar-se-iam conhecimentos desnecessários. $\mathrm{O}$ verdadeiro médico era aquele que conhecia as enfermidades e sabia aplicar remédios específicos para os males. ${ }^{26}$

Em obra que procura reconstituir a história da anatomia e da cirurgia em Portugal, de 1788, o médico Manoel de Sá Mattos deixava evi- 
dente também sua posição favorável aos princípios mecânicos, lançando ataques aos médicos denominados peripatéticos. Ao fazer menção a Brás Luís de Abreu, outro médico português que se vinculava aos princípios galênicos e mágicos da medicina portuguesa, dizia que aquele médico teve a "extravagância de imprimir o seu Portugal Médico", livro que apesar de aludir aos "erros e prejuízos que o vulgo recebe nas suas saúdes", pouco contribuía para o avanço da medicina no Reino. ${ }^{27}$

Francisco da Fonseca Henriques, João Curvo Semedo e Brás Luís de Abreu são exemplos de médicos que compartilhavam a teoria hipocrática e as crenças astrológicas e mágicas comuns à medicina do século XVIII. Se por um lado esses médicos continuaram a exercer influência nas práticas médicas desse período; por outro lado, desde meados do setecentos a tradição de conhecimento em que se assentava a medicina lusa, praticada também na América portuguesa, passou a ser objeto de contestações por parte daqueles que entraram em contato com as inovações da ciência européia e da medicina das Luzes. A partir dos documentos citados, é possível perceber a contraposição aos "antigos", mediante a defesa do experimentalismo, tomando por infundada a medicina praticada até então.

A concepção de ciência da qual compartilhavam os ilustrados em Portugal aponta para a proximidade da Ilustração portuguesa com o Iluminismo no restante da Europa. Ao fazer oposição aos sistemas antigos e reivindicarem o experimentalismo, Luís Antônio Verney, Jacob de Castro Sarmento, Manoel de Sá Mattos, entre outros, agiam de forma semelhante a Galileu, que diferençava os filósofos "naturais" dos "históricos". Os primeiros não necessitavam de nenhum guia, enquanto os "históricos" tinham de se valer da opinião de autoridades para defender se determinado fenômeno era verdadeiro ou falso. A ciência dita "moderna" se constituiu, por um lado, a partir da crítica ao ensino livresco e, por outro, pela defesa na superioridade da técnica e da experimentação. Conforme propõe Paolo Rossi, as conquistas da ciência e da técnica são os testemunhos vivos "da superioridade dos modernos; elas oferecem a prova mais evidente do caráter progressivo do conhecimento". Havia, nesse sentido, a defesa de uma "ideologia da profissão científica" marcada pela rejeição daquilo que se considerava ultrapassado. ${ }^{28} \mathrm{Em}$ Portugal, no período em que estamos abordando, o argumento da técnica, associado ao experimentalismo, forneceu o ponto de partida para as reformas na medicina. 


\section{A reforma do ensino de medicina}

O que significava a adesão aos princípios experimentais das ciências modernas? Em que medida as críticas dos "estrangeirados" tiveram repercussões no ensino de medicina? As respostas a tais questôes podem ser fornecidas, em parte, pelo exame de alguns aspectos dos Estatutos da Universidade de Coimbra de 1772. A reforma da Universidade, bafejada pelas Luzes, procurava se guiar pelo avanço da ciência moderna e pelo racionalismo. Embora a reforma do ensino introduzida pelo grupo dirigente pombalino não tenha rompido de todo com a tradição escolástica, o fato é que a Universidade de Coimbra foi o centro de contato mais avançado do saber ilustrado. ${ }^{29}$ As páginas dos Estatutos dedicadas à medicina colocam em evidência não só a tentativa de transformar os estudos médicos, mas também a de garantir o devido valor às disciplinas até então colocadas em segundo plano, como a anatomia. Da mesma forma, almejava-se que os estudantes tivessem acesso mais à observação e à prática da medicina, valorizando-se, por exemplo, os estudos farmacêuticos e a cirurgia.

Os preparativos para os novos Estatutos se iniciaram pela encomenda à Junta de Providência Literária de um estudo sobre a situação do ensino no Reino, que resultou no Compêndio histórico do estado da Universidade de Coimbra no tempo da invasão dos denominados jesuitas. Verdadeira peça apologética do Iluminismo português, a obra assinalava não só a rejeição aos peripatéticos, mas também a valorização dos progressos das filosofias e físicas mecanicistas para o desenvolvimento dos estudos médicos.

Os médicos se animaram do mesmo espírito geométrico que dirigia os filósofos. E logo se viram nascer deste espírito de clareza, de ordem, e de evidência, multiplicados e sucessivos descobrimentos que deram um conhecimento mais perfeito do mecanismo do corpo. ${ }^{30}$

No Compêndio histórico se exaltavam as figuras de Harvey, Borelli, Boerhaave, entre outros médicos e anatomistas cujos conhecimentos renovaram o conhecimento da medicina. Segundo o documento, durante muito tempo os estudos anatômicos foram impedidos pelas "supertições do tempo sustentadas pelas leis públicas”. O Compêndio histórico acusava os jesuítas pelo atraso dos estudos anatômicos e chegava à conclusão de que embora os livros de Galeno oferecessem preciosas lições sobre o tema, 
elas eram insuficientes. Daí a necessidade da dissecação nos cadáveres, recurso sem o qual seria impossível aprender a "conhecer a estrutura, a configuração, a conexão de qualquer parte do corpo humano como outras partes; mas também a fazer todas as operações próprias desta arte". ${ }^{31}$

A defesa da renovação do ensino médico em Portugal está prenhe de elementos retóricos que deságuam em uma desvalorização da "tradição" galênica, associada à filosofia peripatética. Nesse sentido, é preciso tomar o discurso de cunho ilustrado em sua dimensão retórica, de forma a não esvaziá-lo de seu princípio de defesa de uma outra tradição, a científica moderna, em substituição à escolástica. No caso da medicina e do conhecimento de anatomia, o discurso que emerge das obras de Verney, de Ribeiro Sanches e de diversos tratados médicos encontraria adesão não só na Junta da Providência Literária, como também nos Estatutos da Universidade de Coimbra de 1772, cujo conteúdo corresponde a toda uma plêiade de pensadores ligados às idéias racionalistas e de caráter experimental. ${ }^{32}$

A reforma pombalina dos estudos superiores distribuiu a Universidade de Coimbra nas faculdades de teologia, cânones, leis, medicina, matemática e filosofia. Aprovados em agosto de 1772, os Estatutos da Universidade de Coimbra dedicavam o terceiro capítulo à Faculdade de Medicina. Para cursar medicina, os estudantes deveriam ter certas habilitações, como o conhecimento do latim, grego e filosofia. Em seguida, vinha o curso preparatório de três anos. No primeiro ano, os alunos freqüentariam as cadeiras de geometria e história natural; no segundo, cálculo e física experimental e no terceiro ano, fronomia (ciência do movimento) e química. Após o curso preparatório, o aluno passaria a entrar em contato com disciplinas mais específicas à formação do médico. No primeiro ano do curso, o aluno estudaria a matéria médica, constituída pela história da medicina e o estudo das virtudes de diversas plantas e raízes. $\mathrm{O}$ segundo ano era dedicado inteiramente à anatomia, com aulas práticas no hospital, enquanto o terceiro se ocupava das instituições médicas, em que os alunos aprendiam medicina teórica, fisiologia, patologia, semiologia, higiene e terapêutica. No quarto ano, os alunos estudavam os aforismos de Hipócrates e Boerhaave, enquanto o quinto era dedicado inteiramente ao ensino clínico da medicina e à prática no hospital. ${ }^{33}$ 
Além de colocar em prática algumas idéias e contribuições de Verney e Ribeiro Sanches, os Estatutos destacam a importância da história natural, bem como da física e da química, para o verdadeiro conhecimento do corpo humano. Na esteira da relevância adquirida por essas disciplinas está a valorização de nomes como Newton na física, Harvey na anatomia, Boerhaave em patologia e de Van Swieten em farmacologia, entre outros que renovaram os estudos da medicina européia. Houve também destaque para a construção de laboratórios e estabelecimentos científicos, possibilitando aos alunos colocar em prática as teorias. Para a prática da medicina e da cirurgia foi criado o hospital escolar, local onde se situavam o teatro anatômico e o dispensário farmacêutico. Em acordo com o experimentalismo, priorizava-se a construção de outros estabelecimentos, como o observatório astronômico, um gabinete de história natural e de física experimental, bem como um jardim botânico para uso de estudantes dos diversos cursos. ${ }^{34}$ No caso da medicina se priorizava o ensino da física mecânica e hidráulica, disciplina capaz de comprovar que "as propriedades medicinais dos remédios não são virtudes ocultas, mas conseqüências que resultam das suas propriedades físicas", e que o medicamento agia de forma mecânica sobre o corpo humano, "cuja ação e mecanismo se deve entender" ${ }^{35}$

Os Estatutos da Universidade de Coimbra seguiam a tendência da crítica à cultura livresca, colocando em evidência o conhecimento obtido pela experiência e pela prática. Nesse sentido, tornava-se prioritário cultivar a "medicina empírico-racional", na qual as luzes da teoria seriam úteis para obter as verdades que ensinam "o magistério da natureza"; e as "observaçōes bem-feitas, examinadas e comparadas", serviriam "de retificar, verificar, ampliar, limitar, e aperfeiçoar os conhecimentos da teoria". ${ }^{36} \mathrm{~A}$ junção entre observação e prática consistia, portanto, na base dos estudos médicos almejados pelos reformadores dos Estatutos, o que se verifica na passagem dedicada ao dispensário farmacêutico:

Uma vez por semana fará o [lente de medicina] a lição no Dispensário Farmacêutico. Nele mostrará aos seus discípulos as operações e preparações que em toda a semana lhes tiver explicado no Geral [...] Advertirá, porém, que estas demonstrações práticas não hão de ser oferecidas à vista dos seus 
ouvintes como em espetáculo, mas que os deve obrigar a trabalhar pelas suas mãos dando-lhes para isso ele mesmo o exemplo. ${ }^{37}$

O destaque concedido aos conhecimentos oriundos da prática se estendia igualmente à anatomia. $\mathrm{O}$ acesso dos estudantes aos cadáveres passava a ser prioritário. Segundo os Estatutos para "uso da anatomia, servirão os cadáveres dos que morrerem nos dois hospitais, da universidade e da cidade, e dos que forem justiçados, no caso de havê-los”. Faltando uns e outros, serviriam "os cadáveres de quaisquer pessoas que falecerem na cidade de Coimbra”. Decretava-se, ainda, a continuidade das anatomias praticadas nos animais caso não houvesse corpos à disposição, já que somente neles "se pode observar a natureza obrando as suas principais funçōes" . ${ }^{38}$

Tais determinações significavam um verdadeiro renascimento da anatomia, em Portugal. Afinal, durante boa parte do século XVIII a anatomia galênica serviu de base para o ensino da disciplina na universidade. Apesar dos esforços de d. João V em aprimorar os conhecimentos de anatomia, o próprio monarca, em 1739, baixou um decreto proibindo a dissecação de cadáveres. ${ }^{39}$ A valorização da anatomia nos Estatutos estava, por sua vez, em consonância com o pensamento iluminista do século XVIII. Não é sem razão que a Enciclopédia de Diderot chegava ao extremo de justificar o recurso à dissecação de condenados à morte em proveito dos estudos médicos. Nesse contexto, a prática anatômica passava a ser vista como uma forma de garantir o progresso da arte de curar. ${ }^{40}$

Para as necessidades da prática anatômica, a antiga sala de anatomia deveria ser substituída pelo teatro anatômico, considerado "depois do hospital, o estabelecimento mais necessário e essencial da faculdade”. Sendo a base de toda a cirurgia e da medicina, a anatomia necessitava de um "exercício contínuo de demonstrações feitas nos cadáveres, e das operações executadas neles pelos mesmos estudantes." ${ }^{41}$

O teatro anatômico simboliza um largo conjunto dos ditames médicos mais avançados do final do século XVIII, associando "o ensino prático e a observação dos doentes, dos cadáveres e das suas patologias". ${ }^{42}$ A relevância adquirida pela prática anatômica, em 1772, revelava também o papel primordial da cirurgia na exploração do corpo humano. Até a reforma da universidade, a cirurgia era vista como uma atividade inferior, não sendo digna dos médicos. Aos cirurgiôes delegavam-se atividades relacionadas à mani- 
pulação do corpo humano, como amputações, aplicação de ungüentos, ficando os médicos responsáveis por aviar as receitas. Assim, os ofícios de médico e o de cirurgião, barbeiro e boticário eram diferençados a partir do critério de separação entre ofícios mecânicos e liberais. Enquanto o mundo das ciências e das artes pertencia à física e à medicina dogmática, ofícios como os de cirurgião pertenciam ao ramo das "ciências mecânicas". ${ }^{43}$

Entretanto, a divisão das artes de curar era deplorada por médicos como Ribeiro Sanches, para quem de "todos os estabelecimentos das artes e ofícios que se conservam na República, nenhum se conhece mais indispensável, mais necessário, e mais útil que a cirurgia; ou aquela parte da medicina que cura os males pela operação das mãos" . ${ }^{44}$ Em acordo com as posiçôes de Ribeiro Sanches, os Estatutos enfatizavam os prejuízos acarretados à arte de curar pela separação entre a cirurgia e a medicina. Ao se levar em conta que a distância entre os conhecimentos de cirurgióes e médicos tinha sido prejudicial à arte de curar, ordenava-se que "o estudo da cirurgia prática e especulativa acompanhe sempre o da medicina, e que daqui por diante sejam todos os médicos ao mesmo tempo cirurgiōes". ${ }^{45}$ Conforme observou Rafael Mandressi, não apenas os olhos, mas também as mãos, constituíram-se como os fundamentos da nova ciência anatômica inaugurada no século XVI. A acuidade do olhar e a destreza nas mãos são dois aspectos inseparáveis na exploração dos órgãos do corpo humano, aspectos que mostram a relevância da união entre cirurgia e anatomia. ${ }^{46}$

Entretanto, o reconhecimento da relevância da cirurgia na formação dos médicos não significou a promoção dos cirurgiōes a médicos. A atividade fiscalizadora sobre os que exerciam ofícios de curar sem licença estava prevista no texto dos Estatutos. Seria função da Congregação não consentir mais "exercitar a medicina, e cirurgia pessoas idiotas, por quanto, atendendo eu aos grandes danos, que disto resulta à vida, e saúde" dos vassalos. Toda a pessoa que curasse sem a devida autorização deveria pagar multa de sessenta cruzados (metade para o denunciante) e seria degredado para fora da vila e termo. Reincidentes, pagariam multa em dobro e na terceira vez seriam degredados para a África. Excetuavam-se dessa determinação os médicos e cirurgiōes estrangeiros e "cirurgiôes vulgares, aos quais valerá o estudo que fizerem, [...] para exercitarem sua arte como os limites, que pede a natureza do mesmo estudo, conforme a capacidade lhes é permitido". ${ }^{47}$ 
Documento de caráter normativo, o texto dos Estatutos da Universidade de Coimbra se constitui como elemento de análise relevante, pois permite observar os novos direcionamentos dados ao ensino de medicina. Entretanto, é necessário considerar os obstáculos e limites à implantação dessas reformas. As determinações para a construção de estabelecimentos científicos, laboratórios e do teatro anatômico nem sempre foram colocadas em prática de forma imediata. É o caso, por exemplo, do Hospital Escolar. Institucionalizado em 1772, só começou a funcionar em $1779 .{ }^{48}$ Um outro obstáculo a ser superado consistia na ausência de professores habilitados para ministrar todas as disciplinas. ${ }^{49}$

O próprio currículo do curso de medicina foi alvo de algumas mudanças no ano letivo de 1791-92. Com as modificações, a cadeira de anatomia foi transferida do segundo ano para o primeiro. Avançava-se para o terceiro ano a cadeira de matéria médica e farmácia; preservando os dois últimos anos do curso sem modificaçôes. O novo quadro curricular visava adequar o ensino da medicina ao próprio ato médico. Dessa forma, privilegiava-se, em um primeiro momento, o conhecimento do corpo e a localização espacial da doença; em segundo lugar, destacava-se o conhecimento da gênese e do desenvolvimento das doenças; e, finalmente, davase a conhecer os medicamentos a se utilizar, bem como os modos de preparação dos mesmos. ${ }^{50}$

Não obstante esses aspectos devam ser considerados para a análise das transformações do saber médico em Portugal no setecentos, a intenção neste artigo não é analisar os limites dos Estatutos ou da reforma do ensino médico. Interessa tentar assinalar como, no plano das idéias, em conformidade com o experimentalismo e a anatomia, o mecanismo foi apropriado na medicina portuguesa como perspectiva predominante na investigação das doenças.

\section{O mecanicismo e os estudos anatômicos}

Da mesma forma que os Estatutos da Universidade de Coimbra incorporavam como elemento norteador do ensino de medicina o princípio do experimentalismo a ser aplicado nos estudos farmacêuticos, cirúrgicos e anatômicos, os tratados médicos publicados no período passavam a se 
apropriar das concepções do mecanicismo e aplicá-las ao estudo do corpo humano.

Em linhas gerais, a filosofia mecânica, à qual se vinculam nomes como Galileu, Gassendi, Descartes, Boyle, Newton, entre outros, concebia a natureza a partir de um determinado modelo de funcionamento. Nessa perspectiva de pensamento científico, a física adquiria uma importância fundamental e inúmeros eram os paralelos traçados entre o funcionamento das máquinas e da natureza. Se durante muito tempo a doutrina da analogia entre o microcosmo e o macrocosmo sustentou a idéia de um universo e natureza análogos ao homem, os defensores da filosofia mecânica propunham um método aplicável não só ao mundo da natureza, mas também da vida. Pretendiam, assim, romper com a concepção hierárquica do microcosmo, já que em uma máquina cada peça cumpre função específica. Assim, na máquina do mundo não há mais hierarquias, ou partes mais nobres ou menos nobres; que se aproximavam ou se afastavam de Deus. O desenvolvimento da física no decorrer dos séculos XVII e XVIII exerceu, assim, uma considerável influência sobre o estudo das funções dos órgãos vivos, tornando-se a base da fisiologia. Ao conceber o corpo humano de maneira semelhante às máquinas, a filosofia mecanicista investia contra as antigas teorias sustentadas pela medicina em torno do funcionamento do corpo humano. O questionamento dessas teorias imbricava-se com as descobertas da medicina e com a obra de Descartes. De acordo com o verbete méchanicien da Enciclopédia, a descoberta da circulação do sangue e a filosofia cartesiana abalaram o jugo da autoridade. Adotando o modelo dos geômetras, os médicos modernos submetiam o corpo à investigação da mecânica, considerando o corpo animal, e conseqüentemente o corpo humano, uma verdadeira máquina. ${ }^{51}$

A concepção do corpo-máquina, à qual se vinculavam os médicos na Holanda, França, Itália, entre outros locais da Europa, desde o século XVII, mostrava ser assim uma alternativa para os médicos portugueses que se opunham aos princípios peripatéticos. Nesse aspecto, coube primeiro aos "estrangeirados" não apenas recusar a filosofia peripatética, como também divulgar a percepção do corpo como máquina. Nessa perspectiva, Verney comparava o corpo humano a uma máquina hidráulica, mais perfeita que um relógio, tendo o médico a necessidade de com- 
preender seu mecanismo. "O nosso corpo é uma máquina hidráulica muito mais perfeita que um relógio; pois nele vemos os vasos e fluidos que correm por eles, e os ossos, que sustentam toda a máquina." 52

O lente de anatomia da Universidade de Coimbra, Constâncio, em Anathomia a mais correcta, colhida de vários autores, os mais peritos que desta ciência tem descrevido (1780), sustentava também a idéia de que o corpo humano era "uma máquina muito mais perfeita que um relógio; pois nele vemos uma admirável composição e executarem-se todas as funções destinadas para conservar a vida humana", como demonstravam "os ossos que sustentam toda a máquina, os seus ligamentos, cartilagens, membranas, nervos, artérias, veias, músculos e tegumentos, vemos o coração, e vasos que dele nascem, para fazerem as secreçōes, sanguificaçōes, a circulação" ${ }^{53}$

Ao proporem a comparação do corpo com uma máquina hidráulica, mais perfeita que um relógio, Verney e Constâncio não apenas se filiavam ao mecanicismo, como também demonstravam estar a par da teoria da circulação sanguínea proposta por Harvey, cuja tese dependia da vitalidade da análise hidráulica. Na opinião dos modernos, a obra de Harvey representava um avanço inestimável para o conhecimento do corpo humano, superando em muito os anatomistas antigos. No tempo de Galeno, afirmava Verney, "não faltava quem julgasse que nas artérias não houvesse sangue, e nem menos na aorta". Mas hoje, "descoberta a circulação do sangue, manifesta a anatomia que continuamente corre pelas artérias o sangue". ${ }^{54}$

Referências a nomes como Boyle, Boneli, Vesálio e Harvey passavam a ser recorrentes nos tratados de anatomia e medicina editados em Portugal. É o caso de Jacob de Castro Sarmento, que além de compartilhar dos princípios da "seita experimental" dos filósofos mecânicos, enfatizava as descobertas realizadas desde Vesálio até Harvey. Sobre a arte anatômica, considerava que Vesálio "a trouxe a um grande grau de perfeição", seguido por Colombus e Eustáquio e, sobretudo, o "incomparável e imortal Harvey”, a quem estava reservado o grande feito que foi a descoberta da circulação do sangue. ${ }^{55}$

As pesquisas em anatomia realizadas na Europa desde o século XVI eram apropriadas pelos médicos portugueses que publicaram obras após as reformas pombalinas. Em 1788, Manoel José Leitão também enaltecia a figura de Harvey, afirmando que com ele 
descobre no homem o princípio essencial de todas as funções da nossa máquina. A descoberta da circulação do sangue faz erigir um novo tecido de pensamentos sobre a ruína de tantos sistemas hipotéticos [...] Ele fez compreender aos espíritos menos crédulos pelas experiências mais sensíveis que não é só no bofe que circula o sangue como apenas tinham concebido alguns dos seus predecessores, que circula por todas as partes do corpo humano, com uma ordem admirável. ${ }^{56}$

Nas palavras de Manoel José Leitão se encontra a reafirmação dos pilares da anatomia moderna: a valorização das descobertas como forma de colocar abaixo os sistemas hipotéticos, da experiência como forma de atingir a verdade e a percepção do corpo como uma máquina, cujas funções, conforme afirmava o médico, obedeciam a uma "ordem admirável". Nesse contexto, a anatomia torna-se a ciência que permite ao médico descrever o corpo humano e seus órgãos. Manuel Henriques de Paiva, no Curso de medicina theorica e prática (1792), além de observar que os músculos eram "certas máquinas com que se move o corpo", demonstrava conhecer o funcionamento do coração: "O coração é um músculo oco, assaz irritável posto dentro do peito e dotado da faculdade de encolher-se; a qual mostram os amiudados e sucessivos movimentos, independentes da vontade, desde o primeiro instante da vida animal até a sua morte." ${ }^{57}$

Visto dessa forma, o corpo humano nada mais era do que uma "arquitetura de ossos e de músculos". Ao possibilitar o desmembramento do corpo em diversas partes, a anatomia moderna desfez a ordem cosmológica do homem, tornando-a uma forma presente apenas nas formas populares. ${ }^{58} \mathrm{~A}$ concepção mecanicista do corpo encontrava acolhida em Portugal não só em tratados de médicos portugueses, mas também em obras que passaram a ser traduzidas e publicadas no Reino. O cirurgião Jorge De La Faye, que teve seu Princípios de cirurgia publicado em língua portuguesa em 1787, endossava a idéia sustentada de que o corpo humano era uma máquina animada e que "o conhecimento das mecânicas ajudaria pois bastante para conhecer os movimentos que se executam nesta máquina, quando está bem regulada e porque produzem os efeitos de suas desordens". 59

Nessa perspectiva, o que mantinha o corpo vivo era a vitalidade do funcionamento de seus órgãos. O conhecimento da estrutura interna do corpo humano facultava ao médico os segredos da vida e de sua continui- 
dade. Os estudos anatômicos permitiram não apenas um melhor conhecimento do corpo. Colocavam em evidência também outras perspectivas de se analisar a doença, vista como parte integrante do mecanismo corporal. Nesse sentido, Manuel Henriques de Paiva definia a enfermidade a partir dos sintomas gerais, pois que "afeiçoando toda a máquina perturbam e desordenam geralmente a fábrica e a ordem animal"; e locais, na medida em que "afeiçoam certos órgãos ou partes do corpo, cujos efeitos desarranjam uma ou muitas ações particulares, sem interromperem, nem perturbar a máquina toda”. ${ }^{60}$

No que diz respeito à relação entre o mecanicismo e o estudo das doenças, as idéias de Boerhaave exerceram considerável influência na medicina portuguesa nas últimas décadas do século XVIII. ${ }^{61}$ Sua teoria está entre um dos principais sistemas médicos elaborados no início do século das Luzes. Boerhaave aprimorou a idéia do corpo-máquina, concebendo-o como um conjunto de tubulações feitas de canos e vasos, que continham e canalizavam os líquidos corporais. A saúde resultava da circulação livre dos fluidos no sistema vascular, enquanto a doença era explicada em termos de bloqueio. A idéia do equilíbrio humoral foi preservada, embora fosse traduzida em uma linguagem mecânica e hidrostática. ${ }^{62}$

A primeira obra em português a defender as teorias de Boerhaave foi a já citada Matéria médica de Jacob de Castro Sarmento. ${ }^{63}$ Verney também dedicou inúmeras páginas do Verdadeiro método de estudar ao comentário das idéias de Boerhaave: "Prova muito bem Boerhaave com vários exemplos que, estando inteiro o sólido e líquido no corpo vivente, e somente cessando o movimento, cessa a vida; tornando, ressuscita." ${ }^{64} \mathrm{No}$ Método para aprender e estudar a medicina, Ribeiro Sanches igualmente expôs as lições de Boerhaave. Considerava que este tinha realizado uma síntese completa do estudo do corpo, pois sua análise da doença levava em conta as partes firmes, os sólidos, e as partes líquidas, denominadas humores. Sem a compreensão dos sólidos e dos fluidos a análise da doença ficaria incompleta: "uns, como são os metódicos, tratam das partes sólidas, atribuindo-lhes a causa de todos os males, como se não houvesse humores. Outros tratam somente dos humores, como se não houvesse partes sólidas; como foi Galeno e Avicena”. Assim, embora não descartasse a existência dos humores no corpo humano, Ribeiro Sanches conside- 
rava limitada a medicina galênica e propunha em substituição a teoria de Boerhaave. ${ }^{65}$

Na transição do século XVIII para o XIX, os médicos em Portugal procuravam incorporar em suas obras as teorias da medicina européia, aprofundando o estudo do corpo humano e das causas das doenças. Francisco Soares Franco, demonstrador de anatomia na Universidade de Coimbra em 1800, salientava a relevância dessa parte da ciência médica, "absolutamente necessária ao médico teórico, porque o conhecimento da composição e estrutura dos órgãos deve proceder o estudo de seus usos e funçōes". Fazendo alusão às descobertas realizadas por Morgagni - que buscou por meio de várias autópsias identificar as doenças em órgãos específicos do corpo humano ${ }^{66}-$, Soares Franco avaliava que a aplicação mais relevante da anatomia residia no "seu uso em patologia para determinar as causas e as sedes das moléstias". ${ }^{67}$

Embora a medicina de fins do século XVIII não possa ser reduzida à concepção mecanicista, esta ofereceu uma abertura ao pensamento médico. Os tratados de medicina publicados nesse contexto indicam a incorporação por parte dos médicos dos princípios da reforma do ensino de medicina, fundados no experimentalismo farmacológico e anatômico. Aspecto pouco abordado, a questão do mecanicismo e suas influências no saber médico permitem colocar em foco não apenas as repercussões da Ilustração no saber médico em Portugal, mas também possibilita estabelecer um diálogo com outros estudos sobre as mutações da cultura lusa em fins do setecentos.

\section{Notas}

${ }^{1}$ Entre alguns desses trabalhos, pode-se citar RIBEIRO, Márcia Moisés. A ciência dos trópicos: a arte médica no Brasil do século XVIII. São Paulo: Hucitec, 1997; MARQUES, Vera Regina Beltrão. Natureza em boiōes: medicinas e boticários no Brasil Setecentista. Campinas: Editora da Unicamp, 1999; FERRAZ, Márcia Helena Mendes. As ciências em Portugal e no Brasil (1772-1822): o texto conflituoso da química. São Paulo: Educ, 1997.

${ }^{2}$ A pesquisa em questão é parte do doutorado, realizado no Programa de Pós-Graduação em História da UFMG.

${ }^{3}$ RIBEIRO, Márcia Moisés. Op.cit., p. 73. 
${ }^{4}$ CZERESNIA, Dina. Constituição epidêmica: velho e novo nas teorias e práticas da epidemiologia. História, ciências, saúde Manguinhos, vol. VIII, p. 341-36, jul-ago, 2001.

${ }^{5}$ VILLALTA, Luiz Carlos. Reformismo ilustrado, censura e práticas de leitura: usos do livro na América Portuguesa. Tese de doutorado apresentada à Faculdade de Filosofia e Ciências Humanas da Universidade de São Paulo. São Paulo, 1999, p. 46-54.

${ }^{6}$ SOUZA, A Tavares. Curso de História da medicina. Das origens aos fins do século XVI. Lisboa: Fundação Calouste, 1984, p. 436-445.

7 Sobre os estrangeirados em Portugal ver, entre outros, os estudos de FALCON, José Francisco Calazans. A época pombalina (Política econômica e reformismo ilustrado). São Paulo: Ática, 1982, p. 319-322; GOUVEIA, Antônio Camōes. Estratégias de interiorização da disciplina In: MATTOSO, José (Dir.) História de Portugal O Antigo Regime (1620-1807). Lisboa: Editorial Estampa, 1992, p. 439.

${ }^{8}$ A obra era constituída por um conjunto de dezesseis cartas em que o padre "Barbadinho", pseudônimo sob o qual se disfarçava Verney, dirigia-se a um suposto doutor de Coimbra. Publicada em Nápoles, em 1746, o livro foi retido em Lisboa e enviado aos censores a fim de ser examinado. Em razão do parecer negativo por parte dos censores, o conhecimento e a leitura do Verdadeiro método de estudar ficaram inicialmente restritos a aqueles que a avaliavam. Apesar dos esforços em proibir sua circulação, cinco anos depois era possível encontrar em Lisboa uma edição clandestina da obra. Cf. ANDRADE, Antonio Alberto. Vernei e a cultura de seu tempo. Coimbra: Universidade de Coimbra, 1965, p. 168-183.

${ }^{9}$ GOUVEIA, Antônio Camóes. Op. cit., p. 431-432.

${ }^{10}$ VERNEY, Luís Antônio. Verdadeiro método de estudar [1746]. Vol. IV. Estudos médicos, jurídicos e teológicos. Lisboa: Livraria Sá da Costa, 1950, p. 24.

${ }^{11}$ Para as concepções de saber e as influências da "Ilustração" em Ribeiro Sanches ver, entre outros, o artigo de ARAÚJO, Ana Cristina. Ilustração, pedagogia e ciência em Antônio Nunes Ribeiro Sanches. Revista de História e teoria das idéias. Revoltas e revolução. Coimbra. Faculdade de Letras, Universidade de Coimbra, v. 6, p. 377-395, 1984.

12 SANCHES, Antônio Nunes Ribeiro. Cartas sobre a educação da mocidade [1760]. Coimbra: Imprensa Universitária, 1922, p. 159.

13 SANCHES, Antônio Ribeiro. Método para aprender e estudar a medicina. CovilhãPortugal: Publicação da Universidade da Beira Interior, 2003, p. 1.

${ }^{14}$ Ibidem, p. 20.

${ }^{15}$ Sobre as idéias de Sarmento e suas contribuições à medicina em Portugal ver: DIAS, José Pedro Souza. Jacob de Castro Sarmento e a conversão à ciência moderna. In: Primeiro Encontro de História das Ciências Naturais e da Saúde. Lisboa: Centro de Estudos de História das Ciências Naturais e da Saúde (Instituto de Investigação Científica Bento da Rocha Cabral) e Faculdade de Farmácia da Universidade de Lisboa, p. 55-80.

${ }^{16}$ SARMENTO, Jacob de Castro. Matéria médica physico histórico mechanica. Lisboa: [s. n.], 1758, p. XLV.

TopoI, v. 8, n. 15, jul.-dez. 2007, p. 80-104. 
${ }^{17}$ Ibidem, p. 179.

${ }^{18}$ Ibidem, p. 415.

${ }^{19}$ Embora tenha introduzido substâncias químicas em seus remédios, João Curvo Semedo se vincula à medicina galênica e compunha seus remédios à base de animais e excrementos. Sobre a importância de João Curvo Semedo na medicina portuguesa e a praticada na América Portuguesa ver: RIBEIRO, Márcia Moisés. Op. cit., p. 61-62. MARQUES, Vera Regina Beltrão. Op. cit., p. 267.

${ }^{20}$ Verney, Luís Antônio. Op. cit., p. 53-54.

${ }^{21}$ Ibidem, p. 21.

${ }^{22}$ Ibidem, p. 47-48

${ }^{23}$ RIBEIRO, Márcia Moisés. Exorcistas e demônios demonologia e exorcismo no mundo luso-brasileiro. Rio de Janeiro: Campus, 2003, p. 154-160.

${ }^{24}$ SANCHES, Ribeiro. Apontamentos para estabelecer-se um tribunal e colégio de medicina. Covilhã-Portugal: Publicação da Universidade da Beira Interior, 2003, p. 9.

${ }^{25}$ Sobre a questão dos segredos ver: MARQUES, Vera Regina Beltrão. Op. cit., capítulo 4: Medicamentos de segredo a natureza do espetáculo, p. 235-270.

${ }^{26}$ SANCHES, Ribeiro. Apontamentos para estabelecer-se um tribunal e colégio de medicina. Op. cit., p. 23.

${ }^{27}$ MATTOS, Manoel de Sá. Bibliotheca elementar Chirurgico-anatomica, ou, Compendio histórico - critico, e chronologico sobre a cirurgia e a anatomia. Lisboa. Porto: $\mathrm{Na}$ officina de Antonio Alvarez Ribeiro, 1788, p. 179.

${ }^{28}$ Sobre a defesa dos cientistas de que a ciência moderna era superior a dos "antigos" e a concepção de progresso científico incorporada por cientistas modernos como Bacon, Galileu, Descartes, entre outros ver ROSSI, Paolo. Os filósofos e as máquinas: 14001700. São Paulo: Companhia das Letras, 1989, em particular o capítulo II: A idéia do progresso científico, p. 63-88.

${ }^{29}$ MUNTEAL FILHO, Oswaldo. Domenico Vandelli no anfiteatro da natureza: A cultura cientifica do reformismo ilustrado português na crise do Antigo Sistema Colonial (17991808). Dissertação de Mestrado apresentada ao departamento de História da Pontifícia Universidade Católica. PUC. Rio de Janeiro, 1993, p. 64-65.

${ }^{30}$ Compêndio histórico do estado da Universidade de Coimbra no tempo da invasão dos denominados jesuitas. Lisboa: Na Régia Officina Typográfica, 1771, p. 337.

${ }^{31}$ Ibidem, p. 326

32 CARVALHO, Rômulo de. História do ensino em Portugal: desde a fundação da nacionalidade até o fim do regime de Salazar-Caetano. Lisboa: Fundação Calouste Gulbenkian, 1987, p. 463-465; GOUVEIA, Antônio Camóes. Op. cit., p. 438-439.

${ }^{33}$ A esse respeito ver: PITA, João Rui. Medicina, cirurgia e arte farmacêutica na reforma pombalina da Universidade de Coimbra. In: ARAÜJO, Ana Cristina (Coord.) O marquês de Pombal e a universidade de Coimbra. Coimbra: Imprensa da Universidade, 2000, 
p. 129-162; GUERRA, João Pedro Miller. A reforma pombalina dos estudos médicos In: CARVALHO DOS SANTOS, Maria Helena. Pombal revisitado. Vol.1. Lisboa: Editorial Estampa, 1984, p. 189-207.

${ }^{34}$ CARVALHO, Rômulo de. Op. cit., p. 461-476; GOUVEIA, Antônio Camões. Op. cit., p. 438-439.

${ }^{35}$ Estatutos da Universidade de Coimbra de 1772 - Livro III Cursos das Sciencias naturaes e filosóficas. Coimbra, 1972 (Edição Fac-Símile), p. 21.

${ }^{36}$ Ibidem, p. 18.

${ }^{37}$ Ibidem, p. 33.

38 Ibidem, p. 39-41.

${ }^{39}$ Os motivos para a atitude de d. João V não são explicados pela historiografia. Na obra que escreveu sobre a história da anatomia em Portugal em fins do século XVIII, Manoel José Leitão atribui a atitude de d. João V a uma disputa entre Monravá, médico catalão que pretendia renovar a medicina no Reino, e Santucci, médico italiano convidado pelo monarca para ensinar anatomia em substituição a Monravá. LEITÂO, Manoel José. Tratado completo de anatomia e cirurgia com um resumo da historia da anatomia e Cirurgia seus progressos e estado dela em Portugal offerecido à Real Junta do Proto-Medicato. Lisboa: Antonio Gomes, 1788. 5 Tomos, p. 352-353.

${ }^{40}$ BRETON, David Le. Op. cit., p. 99-100.

${ }^{41}$ Estatutos da Universidade de Coimbra. Op. cit., p. 320.

42 PITA, João Rui. Op. cit., p. 141.

${ }^{43}$ MARQUES, Vera Regina Beltrão. Op. cit., p 163.; RIBEIRO, Márcia Moisés. Op. cit, p. 35.

${ }^{44}$ SANCHES, Antônio Ribeiro. Apontamentos para estabelecer-se tribunal e um colégio de medicina. Covilhã-Portugal: Universidade da Beira Interior, 2003, p. 12.

${ }^{45}$ Estatutos da Universidade de Coimbra. Op. cit., p. 20.

${ }^{46}$ MANDRESSI, Rafael. Dissections et anatomie. In: VIGARELLO, Georges (Dir.) Histoire du corps. De la Renaissance aux Lumières. Paris: Éditions du Seuil, 2005, p. 311-334.

${ }^{47}$ Estatutos da Universidade. Op. cit., p. 134-135.

${ }^{48}$ PITA, João Rui. Op. cit., p. 137-138.

${ }^{49}$ GUERRA, João Pedro Miller. Op. cit., p. 205.

${ }^{50}$ CRESPO, Jorge. A história do corpo. Lisboa: DIFEL, 1990, p. 81-82.

51 Sobre a filosofia mecânica e suas influências na medicina consultar: ROSSI, Paolo.

O nascimento da ciência moderna na Europa. São Paulo: Edusc, 2001, p. 239-270; RUDOLPH, Gerhard. Mesure et expérimentation In: GRMEK, Mirko D. Histoire de la pensée médicale en occident. V. 2. De la renaissance aux lumières. Paris: Étitions du Seuil, 1996, p. 62-66.

${ }^{52}$ VERNEY, Luís Antônio. Op. cit., p. 13. 
53 Apud SANTOS, Sebastião Costa. SANTOS, Sebastião Costa. A escola de cirurgia do Hospital Real de Todos os Santos. Lisboa: Faculdade de Medicina de Lisboa, 1925, p. 181.

${ }^{54}$ VERNEY, Luís Antônio. Op. cit., p. 20.

55 SARMENTO, Jacob de Castro. Op. cit., p. XLIII.

${ }^{56}$ LEITÂO, Manoel José. Op. cit., p. 157.

57 PAIVA, Manuel Henriques de. Curso de medicina theorica e pratica. Lisboa, [s.n.], 1792 , p. 7.

${ }^{58}$ BRETON, David Le. Op. cit., p. 228-229.

${ }^{59}$ LA FAYE, Jorge de. Princípios de cirurgia Nova edição correcta e augmentada, traduzida do Idioma francez em Portuguez por Silvestre José de Carvalho. Lisboa: Simão Tadeo Ferreira, 1787, v. 2, p. XI.

${ }^{60}$ PAIVA, Henriques de. Op. cit., p. 34.

${ }^{61}$ CRESPO, Jorge. Op. cit., p. 68.

${ }^{62}$ Sobre a concepção de Boerhaave ver MAZZOLINI, Renato G. Les lumières de la raison: des systèmes médicaux à l'organologie naturaliste. In: GRMEK, Mirko D. Histoire de la pensée médicale en occident. V. 2. De la renaissance aux lumières. Paris: Étitions du Seuil, 1996, p. 99-101.

${ }^{63}$ DIAS, José Pedro Souza. Op. cit., p. 74.

${ }^{64}$ VERNEY, Luís Antônio. Op. cit, p. 26.

${ }^{65}$ SANCHES, Antônio Ribeiro. Método para aprender e estudar a medicina. Op. cit., p. 30.

${ }^{66}$ MAZZOLINI, Renato G. Op. cit., p. 114-115.

${ }^{67}$ FRANCO, Francisco Soares. Elementos de anatomia. Lisboa: Impressão Régia, 1825. 2 tomos, p. I-II.

\section{Referências bibliográficas}

ANDRADE, Antonio Alberto. Vernei e a cultura de seu tempo. Coimbra: Universidade de Coimbra, 1965.

ARAÚJO, Ana Cristina. Ilustração, pedagogia e ciência em Antônio Nunes Ribeiro Sanches. Revista de História e teoria das idéias. Revoltas e revolução. Coimbra. Faculdade de Letras, Universidade de Coimbra, v. 6, p. 377-395, 1984.

BRETON, David Le. La chair à Vif: usages médicaux et mondains du corps humain. Paris: Métailié, 1993.

CARVALHO, Rômulo de. História do ensino em Portugal: desde a fundação da nacionalidade até o fim do regime de Salazar-Caetano. Lisboa: Fundação Calouste Gulbenkian, 1987.

Compêndio histórico do estado da Universidade de Coimbra no tempo da invasão 
dos denominados jesuitas. Lisboa: Na Régia Officina Typográfica, 1771.

CRESPO, Jorge. A história do corpo. Lisboa: DIFEL, 1990.

CZERESNIA, Dina. Constituição epidêmica: velho e novo nas teorias e práticas da epidemiologia. História, ciências, saúde-Manguinhos, vol. VIII, p. 341-36, jul-ago, 2001.

DIAS, José Pedro Souza. Jacob de Castro Sarmento e a conversão à ciência moderna. In: Primeiro Encontro de História das Ciências Naturais e da Saúde. Lisboa: Centro de Estudos de História das Ciências Naturais e da Saúde (Instituto de Investigação Científica Bento da Rocha Cabral) e Faculdade de Farmácia da Universidade de Lisboa, (s. d.), p. 55-80.

DOMINGUES, Francisco Contente. Ilustração e catolicismo: Teodoro de Almeida. Lisboa: Edições Colibri, 1994.

FALCON, José Francisco Calazans. A época pombalina (Política econômica e reformismo ilustrado). São Paulo: Ática, 1982.

FERRAZ, Márcia Helena Mendes. As ciências em Portugal e no Brasil (17721822): o texto conflituoso da química. São Paulo: Educ, 1997.

FRANCO, Francisco Soares. Elementos de anatomia. Lisboa: Impressão Régia, 1825. 2 tomos.

GOUVEIA, Antônio Camões. Estratégias de interiorização da disciplina In: MATTOSO, José (Dir.) História de Portugal. O Antigo Regime (1620-1807). Lisboa: Editorial Estampa, 1992.

GUERRA, João Pedro Miller. A reforma pombalina dos estudos médicos In: CARVALHO DOS SANTOS, Maria Helena. Pombal revisitado. Vol.1. Lisboa: Editorial Estampa, 1984.

LEITÃO, Manoel José. Tratado completo de anatomia e cirurgia com um resumo da historia da anatomia e Cirurgia seus progressos e estado dela em Portugal offerecido à Real Junta do Proto-Medicato. Lisboa: Antonio Gomes, 1788, 5 t.

MANDRESSI, Rafael. Dissections et anatomie. In: VIGARELLO, Georges (Dir.) Histoire du corps. De la Renaissance aux Lumières. Paris: Éditions du Seuil, 2005, p. 311-334.

MARQUES, Vera Regina Beltrão. Natureza em boiōes: medicinas e boticários no Brasil Setecentista. Campinas: Editora da Unicamp, 1999.

MATTOS, Manoel de Sá. Bibliotheca elementar Chirurgico-anatomica, ou, Compendio histórico - critico, e chronologico sobre a cirurgia e a anatomia. Porto: $\mathrm{Na}$ officina de Antonio Alvarez Ribeiro, 1788.

MAZZOLINI, Renato G. Les lumières de la raison: des systèmes médicaux à 
l'organologie naturaliste. In: GRMEK, Mirko D. Histoire de la pensée médicale en occident. V. 2. De la renaissance aux lumières. Paris: Étitions du Seuil, 1996, p. 93-115.

MUNTEAL FILHO, Oswaldo. Domenico Vandelli no anfiteatro da natureza: A cultura cientifica do reformismo ilustrado português na crise do Antigo Sistema Colonial (1799-1808). Dissertação de Mestrado apresentada ao departamento de História da Pontifícia Universidade Católica. PUC. Rio de Janeiro, 1993.

PAIVA, Manuel Henriques de. Curso de medicina theorica e pratica. Lisboa, [s. n], 1792.

PITA, João Rui. Medicina, cirurgia e arte farmacêutica na reforma pombalina da Universidade de Coimbra In: ARAÜJO, Ana Cristina (Coord.) O marquês de Pombal e a universidade de Coimbra. Coimbra: Imprensa da Universidade, 2000, p. 129-162.

PORTER, Roy. Das tripas coração: Uma breve história da medicina. Rio de Janeiro: Record, 2004.

RIBEIRO, Márcia Moisés. A ciência dos trópicos: a arte médica no Brasil do século XVIII. São Paulo: Hucitec, 1997.

. Exorcistas e demônios: demonologia e exorcismo no mundo luso-bra-

sileiro. Rio de Janeiro: Campus, 2003.

ROSSI, Paolo. O nascimento da ciência moderna na Europa. São Paulo: Edusc, 2001.

Letras, 1989. . Os filósofos e as máquinas: 1400-1700. São Paulo: Companhia das

RUDOLPH, Gerhard. Mesure et expérimentation. In: GRMEK, Mirko D. Histoire de la pensée médicale en occident. De la renaissance aux lumières. Paris: Étitions du Seuil, 1996, p. 61-92.

SANCHES, Antônio Nunes Ribeiro. Cartas sobre a educação da mocidade, [1760]. Coimbra: Imprensa Universitária, 1922.

SANCHES, Antônio Ribeiro. Apontamentos para estabelecer-se tribunal e um colégio de medicina. Covilhã-Portugal: Universidade da Beira Interior, 2003. . Método para aprender e estudar a medicina. Covilhã-Portugal: Universidade de Beira Interior, 2003.

SANTOS, Sebastião Costa. A escola de cirurgia do hospital real de todos os santos. Lisboa: Faculdade de Medicina de Lisboa, 1925.

SARMENTO, Jacob de Castro. Matéria medica physico histórico mechanica. Lisboa: [s. n.], 1758.

SOUZA, A Tavares. Curso de história da medicina. Das origens aos fins do século 
XVI. Lisboa: Fundação Calouste Gulbenkian, 1984.

VERNEY, Luís Antônio. Verdadeiro método de estudar [1746]. Vol. IV. Estudos médicos, jurídicos e teológicos. Lisboa: Livraria Sá da Costa, 1950.

VILLALTA, Luiz Carlos. Reformismo ilustrado, censura e práticas de leitura: usos do livro na América Portuguesa. Tese de doutorado apresentada à Faculdade de Filosofia e Ciências Humanas da Universidade de São Paulo, São Paulo, 1999.

\section{RESUMO}

Nas últimas décadas, um dos temas da historiografia luso-brasileira tem sido o das relaçôes entre a medicina e a cultura científica no século XVIII. Parte de uma pesquisa mais ampla sobre o tema, este artigo apresenta algumas consideraçôes acerca da influência do experimentalismo e do mecanicismo no saber médico do período. Nesse sentido, propomos analisar a crítica dos "estrangeirados" à tradição galênica, o papel da reforma dos Estatutos da Universidade de Coimbra, de 1772, e a influência do mecanicismo na anatomia. O objetivo principal é o de contribuir para a compreensão das transformações do saber médico no contexto da Ilustração em Portugal. Palavras-chave: medicina, experimentalismo, Ilustração.

\section{ABSTRACT}

During the last decades, the Brazilian and Portuguese historiography has approached the relationship between medicine and scientific culture in the XVIII century. As a part of a larger research, this article presents some comments about the influence of experimentalism and mechanicism upon the medical knowledge during that time. Hence, I propose to analyze the "outsiders" critic to Galenian tradition, the role of the Reform in the University of Coimbra statutes of 1772, and the influence of mechanicism in anatomics. The main goal of this article is to contribute to a better understanding of the changes in medical knowledge during Portugal's Enlightenment. Keywords: medicine, experimentalism and Enlightenment.

Recebido em agosto de 2006 e aprovado em março de 2007 